\title{
Lessons from the Interagency Emergency Health Kit for access to essential medicines in Canada
}

Adam R. Houston ${ }^{1 *}$ (D) and Jason W. Nickerson ${ }^{2,3}$

\begin{abstract}
Despite Canada's efforts to position itself as a global health leader, important medicines, including multiple drugs found on the WHO Model List of Essential Medicines, are not available domestically. Of the fourteen medicines found in the Interagency Emergency Health Kit, the most basic distillation of the global health toolkit designed for responding to acute humanitarian crises, only ten are currently sold in Canada; alternative treatments that are available may not be as effective or affordable. Their absence highlights broader issues with Canada's market-driven system of access to medicines, with implications for the care of refugees and other populations, while serving as a reminder of the importance of ensuring access to essential medicines in all settings.
\end{abstract}

Keywords: Essential medicines, Canada, Interagency Emergency Health Kit

\section{Introduction}

For many years, Canada has aspired to position itself as a leader in global health and humanitarianism, prioritizing diverse but related initiatives including access to medicines, humanitarian assistance, and accepting refugees, to varying success (Nixon et al. 2018). Paradoxically, the fact that many low-cost medicines that are essential to the delivery of health programming in developing countries-and which are needed by hundreds of patients a year in Canada for the same conditions-are difficult to access in Canada has prompted little action. This includes numerous drugs found on the World Health Organization's Model List of Essential Medicines, which outlines the basic medicines every health system should have access to (WHO 2017). The problem is not restricted to rare or neglected diseases. For instance, Canada records over 1500 cases of tuberculosis each year (Vachon et al. 2018), yet multiple essential medicines for TB are not even registered in Canada, despite being included in Canada's national treatment guidelines (Public Health Agency of Canada 2014). This is the case even as Canada has been a major funder of initiatives like the Global Drug Facility (GDF) to promote access to

\footnotetext{
* Correspondence: ahous062@uottawa.ca

${ }^{1}$ Faculty of Law, University of Ottawa, Ottawa, Canada

Full list of author information is available at the end of the article
}

these same drugs elsewhere in the world (Government of Canada n.d.). To illustrate domestic access gaps around these basic global public health tools, one need look no further than the basic Interagency Emergency Health Kit.

\section{The Interagency Emergency Health Kit}

The product of a collaboration between key organizations such as the World Health Organization (WHO), the International Federation of Red Cross and Red Crescent Societies, UNICEF, Médecins Sans Frontières, and the United Nations High Commissioner for Refugees, the kit is designed to be usable under emergency circumstances in the absence of doctors or nurses by health workers with limited training (Interagency Emergency Health Kit 2017). It contains the supplies necessary to quickly respond to persistent and common public health problems during acute crises. One basic kit is intended to serve 1000 people for 3 months; it contains such rudimentary tools as cotton wool, scissors, soap, bandages, and pens and notebooks for record keeping. It also contains a handful of medicines, all of which are found on the WHO List. The kit whittles that list down to its essence, from over 400 drugs to a mere 14 . 
Included are staples familiar to any Canadian medicine cabinet, like ibuprofen and acetaminophen. At the same time, the kit also provides a glimpse at a persistent and growing problem in Canada: many effective medicines that are common elsewhere in the world are simply unavailable here. A search of Health Canada's Drug Product Database, which lists drugs approved for use in Canada (Health Canada Drug Product Database 2018), reveals that of the fourteen different medications contained in the kit (two of which are included in multiple formulations), only ten are currently sold in the country (Table 1). In other words, four medicines considered as basic and as important as ibuprofen and acetaminophen are not sold here.

The gaps in access include drugs that are basic staples of primary care in many countries, including albendazole, which is the standard treatment for a range of parasites and which costs pennies a dose in much of the world (International Medicine Products Price Guide 2015). Some parasitic conditions, like strongyloidiasis, are relatively uncommon in Canadian-born populations, but common in populations who emigrate to Canada from parts of the world where they are endemic, leading to Canadian recommendations that refugees arriving from Africa and Southeast Asia should be screened for them (Pottie et al. 2011). Paradoxically, the Canadian clinical guidelines for immigrants and refugees recommend the use of either albendazole or, depending on the clinical situation, ivermectin, another key drug in many global health interventions, even though both drugs were unavailable in Canada at the time the guidelines were crafted (ivermectin only received approval in Canada in
September 2018, decades after it entered into use elsewhere, after a pharmaceutical company finally decided to apply for Canadian registration (Health Canada, Product Information 2018)). Thus, newly arrived refugees face the unusual situation of potentially requiring drugs unavailable to them in Canada, yet which are both widely available on international markets and included in the most basic medical supply kit-the Interagency Kit-for crisis situations such as those many refugees may be leaving behind. Both of these drugs are also useful-or would be, were they available-in treating a variety of parasitic diseases native to Canada. Currently, however, albendazole and many other essential medicines are only available through Health Canada's Special Access Programme (SAP), a regulatory pathway designed to provide access to new drugs that companies have not yet brought to market in Canada, which is more cumbersome than simply having essential drugs of proven efficacy available for sale or importable on demand, and has led to numerous access issues (Houston et al. 2018).

Similarly, although not endemic to Canada, approximately 400 to 500 cases of malaria are diagnosed here each year (Boggild et al. 2017). Artemether/lumefantrine is a drug of choice for treatment of uncomplicated $P$. falciparum malaria in much of the world (World Health Organization and Global Malaria Programme 2015). Artemether is a derivative of artemisinin, whose discoverers won the Nobel Prize in 2015; coincidentally, they shared the prize with the discoverers of ivermectin (The Nobel Prize in Physiology or Medicine 2015). Nevertheless, while patients in Canada do have other treatment options such as atovaquone-proguanil, the globally

Table 1 Canadian approval status of Interagency Emergency Health Kit drugs

\begin{tabular}{|c|c|c|}
\hline Drug & Unit & Approval in Canada \\
\hline Albendazole, chewable tablet 400 mg & Tablet & No \\
\hline Omeprazole, solid oral dosage form 20 mg & Tablet/capsule & Yes \\
\hline Amoxicillin, dispersible tablet 250 mg & Tablet & Yes \\
\hline Benzyl benzoate, lotion 25\% & Bottle 11 & No \\
\hline Chlorhexidine gluconate, solution $5 \%$ & Bottle 1 I & Yes \\
\hline Ferrous sulfate + folic acid, tablet 200 mg + 0.4 mg & Tablet & Yes \\
\hline Ibuprofen, tablet 200 mg & Tablet & Yes \\
\hline Miconazole nitrate, cream 2\% & Tube $30 \mathrm{~g}$ & Yes \\
\hline ORS (Oral Rehydration Salt), powder for dilution & Sachet for 11 & Yes \\
\hline Paracetamol (aka Acetaminophen), tablet 100 mg and 500 mg & Tablet (two strengths) & Yes \\
\hline Povidone-iodine, solution 10\% & Bottle $200 \mathrm{ml}$ & Yes \\
\hline Tetracycline, eye ointment 1\% & Tube $5 \mathrm{~g}$ & No* (status: dormant) \\
\hline Zinc sulfate, dispersible tablet 20 mg & Tablet & Yes \\
\hline \multicolumn{3}{|l|}{ Malaria module (can be withheld from the order upon request) } \\
\hline Artemether + lumefantrine, tablet and dispersible tablet, $20 \mathrm{mg}+120 \mathrm{mg}$ & Dispersible tablet and tablet & No \\
\hline
\end{tabular}

*The manufacturer's website was consulted to confirm that tetracycline eye ointment $1 \%$ is not currently being sold (Sterigen-Products 2018 ) 
preferred treatment remains unavailable in Canada, even while it is accessible in many of the countries where the disease could have been contracted.

Of the others, benzyl benzoate lotion is used to treat lice and scabies. The Canadian Pediatric Society notes benzyl benzoate offers high efficacy at a low cost and is widely used outside North America; in Canada, the go-to treatment is permethrin, which is similarly effective, but costs more (Banerji 2015). Similarly, Canadians have options other than tetracycline eye ointment to treat eye infections. However, recent shortages of alternative products such as erythromycin underscore the value of having a range of treatment options available (Drug Shortages Canada 2018).

\section{Access to essential medicines in Canada}

Four medicines may seem insignificant given that the Canadian pharmacopeia includes thousands of drugs, including alternatives-albeit often more expensive while potentially no more effective-to those highlighted here. However, these four medicines are but the tip of the iceberg. All of the medicines in the kit, like many of the other essential medicines not marketed in Canada, are not currently under patent. They are all of proven utility. Ultimately, the problem is that some medicines of sufficient value to be named WHO Essential Medicines are absent from Canada not because they lack usefulness, or due to patent-created monopolies, but largely because drug companies judge these old, off-patent medicines insufficiently profitable in the Canadian market and therefore do not register them here. A similar problem afflicts a range of other medicines serving small patient populations, which are routinely not registered here, or whose registration is given a lower priority than in larger more lucrative markets. Drugs for rare diseases are the most glaring example, with treatments, both old and new, often available only through the SAP or other means such as $N=1$ trials. The situation leaves policymakers in a difficult position, with few tools for compelling drug makers to register and sell important medicines, generic or patented, in the Canadian market.

Political pressures have prompted recent changes to make unregistered drugs more readily accessible, but the scope has been narrow. For example, in direct response to the opioid crisis, Canada introduced a new mechanism to permit the short-term importation of drugs unregistered in Canada, but approved in the USA, European Union, or Switzerland, to address an "urgent public health need." The introduction of this new Access to Drugs in Exceptional Circumstances mechanism was accompanied by a Regulatory Impact Statement explicitly acknowledging that some treatments are not sold in Canada as a direct consequence of the business preferences of pharmaceutical companies (Regulations Amending the Food and Drug
Regulations 2017). Essentially, it recognizes that pharmaceutical companies choose not to make products, whether generic or under patent, available in markets that are deemed insufficiently profitable, even when a public health need for them exists.

Although designed for the opioid crisis, this new mechanism has been quickly seized upon for treating conditions that have not received similar government attention. As of December 2018, only three Canadian health jurisdictions had requested access to opioid treatments under the new regime; by the same point in time, despite tuberculosis being absent from the government's agenda in developing the new mechanism, 11 jurisdictions had requested access to rifapentine, an essential medicine for treating latent TB, in what the updated list of requests explicitly terms the "tuberculosis crisis" (Health Canada 2018). As with the SAP, healthcare providers have to rely on ill-fitting mechanisms to obtain essential medicines that any health system should have access to.

\section{Conclusions}

The Interagency Emergency Health Kit offers a revealing glimpse at the disconnect between Canada's efforts to address access to medicines in its global health and humanitarian programming abroad and the ongoing domestic barriers to accessing essential medicines at home. It serves as a reminder that the importance of access to basic health tools may be most apparent in a humanitarian emergency, but that access challenges also exist in high-income countries and ensuring ongoing access to these tools to all who need them should remain a global priority. The issues raised go well beyond the scope of the medicines in the kit, however, and warrant further study to understand the full impact of access barriers on patients and health systems and to understand what tools-if any-governments may have to ensure that important drugs of proven global utility are made accessible and affordable wherever they are needed.

Emerging domestic tools like the Access to Drugs in Exceptional Circumstances mechanism show that where an issue (like the opioid crisis) receives political attention, it is entirely possible for Canada to craft regulatory pathways to improve access to drugs even where there has been little interest in commercial registration; refining such tools to better encompass essential medicines that fill an unprofitable but medically important niche is one possible avenue. Similarly, international mechanisms like the GDF for tuberculosis show that it is possible to pool multiple markets to ensure sustainable production of affordable essential medicines of assured quality; in turn, shifting Canadian policy towards obtaining drugs from the same mechanism it already supports financially may also help ensure sustainable Canadian support for 
the GDF. Moving forward, promoting the expansion of pooled drug production at the international level for conditions other than TB, coupled with either improved domestic tools for accessing unregistered essential medicines, or alternate pathways to domestic registration for drugs whose public health utility outweighs their commercial viability, would be a chance for Canada to assume a leadership role in global health while also ensuring the benefits it promotes abroad are shared at home.

\section{Abbreviations}

GDF: Global Drug Facility; SAP: Special Access Programme; WHO: World Health Organization

\section{Acknowledgements}

$\mathrm{ARH}$ - None.

JWN - None.

\section{Funding}

No funding was received for this project.

\section{Availability of data and materials}

All data generated or analysed during this study are included in this published article.

\section{Authors' contributions}

ARH proposed the topic, wrote the initial draft, and conducted subsequent revisions. JWN provided major contributions to the refining of the topic and revising of the paper. Both authors read and approved the final manuscript.

\section{Competing interests}

The authors declare that they have no competing interests.

\section{Publisher's Note}

Springer Nature remains neutral with regard to jurisdictional claims in published maps and institutional affiliations.

\section{Author details}

${ }^{1}$ Faculty of Law, University of Ottawa, Ottawa, Canada. ${ }^{2}$ Bruyère Research Institute, Ottawa, Canada. ${ }^{3}$ Centre for Health Law, Policy and Ethics, Faculty of Law, University of Ottawa, Ottawa, Canada.

Received: 14 October 2018 Accepted: 6 January 2019

Published online: 16 January 2019

\section{References}

Banerji A. 'Scabies' (2015) Paediatrics \& Child Health 20 395. https://www.cps.ca/ en/documents/position/scabies

Boggild AK et al (2017) Underestimate of annual malaria imports to Canada. Lancet Infect Dis 17:141-142

Drug Shortages Canada https://www.drugshortagescanada.ca/. Accessed 1 Oct 2018

Government of Canada (n.d.) Project profile — Global Drug Facility: Provision of Anti-Tuberculosis Drugs. http://w05.international.gc.ca/projectbrowserbanqueprojets/project-projet/details/m011474003. Accessed 1 Oct 2018.

Health Canada, List of Drugs for an Urgent Public Health Need https://www. canada.ca/en/health-canada/services/drugs-health-products/access-drugsexceptional-circumstances/list-drugs-urgent-public-health-need.html. Accessed 15 Dec 2018

Health Canada Drug Product Database https:/www.canada.ca/en/health-canada/ services/drugs-health-products/drug-products/drug-product-database.html. Accessed 1 Oct 2018

Health Canada, Product Information: Stromectol (2018-09-05), https://healthproducts.canada.ca/dpd-bdpp/info.do?lang=en\&code $=97110$. Accessed 1 Oct 2018

Houston AR et al (2018) Reforming Canada's special access Programme (SAP) to improve access to off-patent essential medicines. JAMMI 3:100-107
Interagency Emergency Health Kit 2017 http://www.who.int/emergencies/kits/ iehk/en/

International Medicine Products Price Guide (2015) http://mshpriceguide.org/en/ single-drug-information/?DMFId=1262\&searchYear=2015

Nixon SA et al (2018) Canada's global health role: supporting equity and global citizenship as a middle power. Lancet 391:1736-1748

Pottie K et al (2011) Evidence-based clinical guidelines for immigrants and refugees. CMAJ 183:E824

Public Health Agency of Canada (2014) Canadian tuberculosis standards. In: Minister of public works and government services, 7th edn https://www. canada.ca/content/dam/phac-aspc/migration/phac-aspc/tbpc-latb/pubs/tbcanada-7/assets/pdf/tb-standards-tb-normes-ch8-eng.pdf

Regulations Amending the Food and Drug Regulations (Importation of Drugs for an Urgent Public Health Need), Canada Gazette April 22, 2017 Vol. 151. http://www.gazette.gc.ca/rp-pr/p1/2017/2017-04-22/html/reg3-eng.html

Sterigen - Products http://www.sterigen.com/en_products.html Accessed 1 Oct 2018

The Nobel Prize in Physiology or Medicine 2015 (2015) http://www.nobelprize. org/nobel_prizes/medicine/laureates/2015/

Vachon J, Gallant V, Siu W (2018) Tuberculosis in Canada, 2016. Can Commun Dis Rep 44(3/4):75-81

WHO Model List of Essential Medicines, $20^{\text {th }}$ ed. (March 2017) http://www.who. int/medicines/publications/essentialmedicines/en/

World Health Organization and Global Malaria Programme (2015) Guidelines for the treatment of malaria. http://www.ncbi.nlm.nih.gov/books/NBK294440/. Accessed 23 June 2018

\section{Submit your manuscript to a SpringerOpen ${ }^{\circ}$ journal and benefit from:}

- Convenient online submission

- Rigorous peer review

- Open access: articles freely available online

High visibility within the field

- Retaining the copyright to your article

Submit your next manuscript at $\boldsymbol{\nabla}$ springeropen.com 